Check for updates

Cite this: RSC Adv., 2020, 10, 30785

\title{
Curcumin loaded zinc oxide nanoparticles for activity-enhanced antibacterial and anticancer applications $\dagger$
}

\author{
W. P. T. D. Perera, (D) ab Ranga K. Dissanayake, (D) ${ }^{* b c}$ U. I. Ranatunga, ${ }^{d}$ \\ N. M. Hettiarachchi, ${ }^{a b}$ K. D. C. Perera, (D) ${ }^{\text {ab }}$ Janitha M. Unagolla, ${ }^{\text {e R. T. De Silva }}{ }^{b}$ \\ and L. R. Pahalagedarab
}

Zinc oxide nanoparticles and curcumin have been shown to be excellent antimicrobial agents and promising anticancer agents, both on their own as well as in combination. Together, they have potential as alternatives/supplements to antibiotics and traditional anticancer drugs. In this study, different morphologies of zinc oxide-grafted curcumin nanocomposites (ZNP-Cs) were synthesized and characterized using SEM, TGA, FTIR, XRD and UV-vis spectrophotometry. Antimicrobial assays were conducted against both Gram negative and Gram-positive bacterial stains. Spherical ZnO-curcumin nanoparticles (SZNP-Cs) and rod-shaped ZnO-curcumin nanoparticles showed the most promising activity against tested bacterial strains. The inhibition zones for these curcumin-loaded $\mathrm{ZnO}$ nanocomposites were consistently larger than their bare counterparts or pure curcumin, revealing an additve effect between the $\mathrm{ZnO}$ and curcumin components. The potential anticancer activity of the synthesized nanocomposites was studied on the rhabdomyosarcoma RD cell line via MTT assay, while their cytotoxic effects were tested against human embryonic kidney cells using the resazurin assay. SZNP-Cs exhibited the best balance between the two, showing the lowest toxicity against healthy cells and good anticancer activity. The results of this investigation demonstrate that the nanomatrix synthesized can act as an effective, additively-enhanced combination delivery/therapeutic agent, holding promise for anticancer therapy and other biomedical applications.

Received 1st July 2020

Accepted 12th August 2020

DOI: 10.1039/dOra05755j

rsc.li/rsc-advances

\section{Introduction}

Medicinal plants serve as nature's gift to humanity, aiding in the pursuit for better health; plants and their bioactive metabolites have been used in medicinal practices around the world since antiquity. ${ }^{1}$ Phytochemicals have seen a steady rise in popularity in the recent past with the introduction of a range of nutraceuticals and herbal medications into the market. There are several phytochemicals that have scientifically proven bioactive potential, which can serve as an alternative strategy for

\footnotetext{
${ }^{a}$ Academy of the Sri Lanka Institute of Nanotechnology, Nanotechnology and Science Park, Mahenwatte, Pitipana, Homagama 10206, Sri Lanka

${ }^{b}$ Sri Lanka Institute of Nanotechnology, Nanotechnology and Science Park, Mahenwatte, Pitipana, Homagama 10206, Sri Lanka

'Department of Pharmacy and Pharmaceutical Sciences, Faculty of Allied Health Sciences, University of Sri Jayewardenepura, Gangodawila, Nugegoda 10250, Sri Lanka.E-mail: rangad@sjp.ac.lk

${ }^{d}$ Department of Biochemistry and Molecular Biology, Faculty of Medicine, University of Colombo, 25 Kynsey Road, Colombo 00800, Sri Lanka

${ }^{e}$ Biomedical Engineering Program, Department of Bioengineering, College of Engineering, University of Toledo, Toledo, $\mathrm{OH} 43607$, USA

$\dagger$ Electronic supplementary information (ESI) available. See DOI: 10.1039/d0ra05755j
}

controlling the initiation and progression of common diseases. Among them are compounds such as curcumin, resveratrol, linamarin, cyanidin, apigenin, flavopiridol, epigallocatechin gallate (EGCG), and indole-3-carbinol. ${ }^{2}$

Of the potent bioactive metabolites that have been identified from plant sources, curcumin is one of the most-investigated. ${ }^{2}$ Named [1,7-bis(4-hydroxy-3-methoxyphenyl)-1,6-heptadiene3,5-dione] under the IUPAC system, it is a polyphenolic, hydrophobic yellow pigment derived from the rhizome of the well-known spice plant turmeric (Curcuma longa L.). ${ }^{3,4}$ It is a mixture of three curcuminoids: diferuloylmethane (curcumin proper), demethoxycurcumin and bisdemethoxycurcumin. Curcumin exhibits keto-enol tautomerism, having a predominant keto form in acidic/neutral solutions and a stable enol form in alkaline media. ${ }^{5,6}$ Research over the last two decades has shown it to be a potent antioxidant, anti-inflammatory, antiproliferative, antimetastatic, antiangiogenic, antidiabetic, hepatoprotective, antiatherosclerotic, antithrombotic, and antiarthritic agent in cell- and animal studies. ${ }^{4}$

Although curcumin has exhibited potent biological activities in vitro, it has managed to show only low activity in various clinical studies. This is mainly due to the poor bioavailability of curcumin, contributed to by its insolubility, instability, poor 
absorption, and rapid biotransformation., ${ }^{3,7}$ Curcumin is therefore designated as a typical class IV Biopharmaceutical Classification System (BCS) molecule, which exhibit many characteristics that are problematic for effective oral delivery with poor pharmacokinetics. ${ }^{\mathbf{8 9}}$ Various drug delivery systems such as nanoparticles, ${ }^{\mathbf{1 0 - 1 2}}$ liposomes, ${ }^{\mathbf{1 2 - 1 5}}$ microparticles, ${ }^{13}$ microemulsion $^{16}$ and implants ${ }^{17,18}$ have been shown to significantly enhance preventive/therapeutic efficacy by increasing the drugs' bioavailability and targetability.,19 The work outlined herein has chosen zinc oxide ( $\mathrm{ZnO}$ ) nanoparticles to work with, predominantly due to their well-understood properties (both physical and biological), and an existing basis in literature for combination with curcumin.

$\mathrm{ZnO}$ is biocompatible-its common spherical nanoformulation is considered to be non-toxic and nonimmunogenic as well and is a cost-effective starting material. ${ }^{9}$ It has been found to induce necrotic- and apoptotic pathways in cancer cells via the disruption of the cell membrane and reduction of the mitochondrial membrane potential. ${ }^{20}$ The latter increases levels of intracellular reactive oxygen species (ROS) and triggers the mitochondria subsidiary apoptotic pathway. ZnO nanoparticles' antibacterial effects are produced in a similar way, enhanced by an abrasive surface created by surface defects. ${ }^{21}$ The ability of ZnO nanoparticles (ZNPs) to produce ROS and attack pathogenic microorganisms in particular has been well-documented in literature through the years. ${ }^{22-24}$ Incorporation of curcumin into this system will likely improve these properties via a possible additive effect; extant literature has already shown that ZnO-coupled curcumin has a significantly higher bioavailability than free curcumin. Another point of interest is that ZNPs have been shown to be pH-sensitive, dissociating into $\mathrm{Zn}^{2+}$ at low $\mathrm{pH}$ values. ${ }^{21}$ The acidic tumor microenvironment is expected to produce similar results, aiding in the release of surface-bound curcumin withinor around the tumor. ${ }^{4}$

In the present study, the physical-, chemical- and morphological properties, and antibacterial-, anticancer- and cytotoxic effects of a range of $\mathrm{ZnO}$ nanoparticle morphologies and their curcumin-grafted counterparts were examined. These were developed to improve the bioavailability, stability, solubility, and dosage of the individual components to enhance their bioactivities. The nanocomposites include spherical- (SZNP-C), rod- (RZNP-C), javelin- (JZNP-C), short petal- (SPZNP-C), and long petal- (LPZNP-C) morphologies. While several works have investigated the delivery properties of multiple morphologies of zinc oxide nanoparticles and nanocomposites for a variety of drugs and nutraceuticals, this is the first time a range of such curcumin-grafted morphologies are being subjected to a standardized method.

\section{Experimental procedure}

\section{Materials}

Zinc nitrate, sodium hydroxide, cetyltrimethylammonium chloride (CTAC; molecular weight of 10000 ), polyethylene glycol (PEG; molecular weight of 4000), starch and curcumin were purchased from Sigma-Aldrich (USA). The antimicrobial compound cloxacillin sodium was gifted by the State Pharmaceutical Manufacturing Corporation of Sri Lanka. MuellerHinton agar (Hardy, USA) and phosphate buffered saline (Sigma, USA) were used for microbiology studies. Dulbecco's Modified Eagle Medium (with L-glutamine and nonessential amino acids), Hanks Buffered Salt Solution (HBSS), fetal bovine serum (FBS) and trypsin were purchased from Sigma-Aldrich (USA) for anticancer studies, along with cycloheximide (Himedia, India).

\section{Synthesis of ZnO nanoparticles}

Synthesis of spherical shaped ZnO nanoparticles (SZNP). Nanoparticles were synthesized using aqueous solutions of zinc nitrate hexahydrate $\left(\mathrm{Zn}\left(\mathrm{NO}_{3}\right)_{2} \cdot 6 \mathrm{H}_{2} \mathrm{O}\right)$ and sodium hydroxide $(\mathrm{NaOH})$. Separate solutions of the two were made in a molar ratio of $1: 2$ in distilled water (Fig. 1). The zinc nitrate solution was mixed with a CTAC solution and stirred until homogenous. The $\mathrm{NaOH}$ was then added dropwise into the zinc nitrate/CTAC solution, and the particles collected by centrifugation (10 000 $\mathrm{rpm})$. The pellet was oven-dried overnight at $60{ }^{\circ} \mathrm{C} .{ }^{25}$

Synthesis of javelin-shaped ZnO nanoparticles (JZNP). $\mathrm{Zn}\left(\mathrm{NO}_{3}\right)_{2}$ and $\mathrm{NaOH}$ were dissolved together in distilled water in a $1: 2$ molar ratio (Fig. 1). The mixture was stirred rapidly at room temperature over 12 hours. The sample was then centrifuged (10 $000 \mathrm{rpm}$ ) and washed thrice with water and once with ethanol. The final product was collected by oven-drying the centrifuged pellet overnight at $60{ }^{\circ} \mathrm{C} .^{26}$

Synthesis of short petal-shaped ZnO nanoparticles (SPZNP). An $8 \%$ solution of polyethylene glycol (PEG) was made in $100 \mathrm{~mL}$ of distilled water. $\mathrm{Zn}\left(\mathrm{NO}_{3}\right)_{2}$ was added to the PEG solution and stirred until fully dissolved, followed by the addition of $\mathrm{OH}^{-}$such that the final molar ratio of $\mathrm{Zn}^{2+}: \mathrm{OH}^{-}$was $3: 1$ (Fig. 1). This mixture was heated to $70{ }^{\circ} \mathrm{C}$ under rapid stirring for 15 minutes. Once cooled to room temperature, the $\mathrm{pH}$ of the solution was adjusted to $\mathrm{pH} 11$ using a $1 \mathrm{M} \mathrm{NaOH}$ solution. The resultant solution was centrifuged (10 $000 \mathrm{rpm})$ and washed thrice with distilled water and once with ethanol.

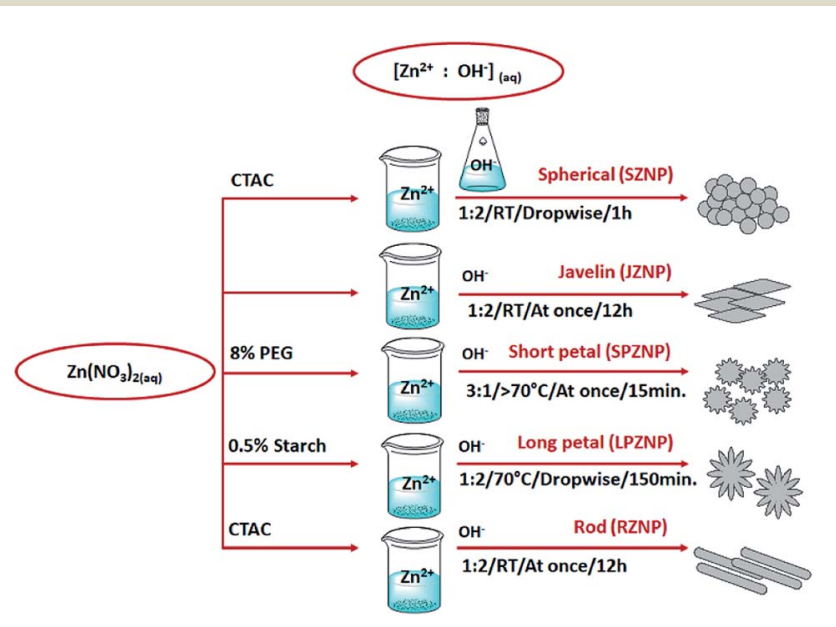

Fig. 1 Schematic steps involved in the synthesis of polymorphic $\mathrm{ZnO}$ nanoparticles. 
The final product was collected by oven-drying the centrifuged pellet overnight at $60{ }^{\circ} \mathrm{C}^{27}$

Synthesis of long petal-shaped ZnO nanoparticles (LPZNP). Solutions of $\mathrm{Zn}\left(\mathrm{NO}_{3}\right)_{2}$ and $\mathrm{NaOH}$ were made separately in distilled water in a $1: 2$ molar ratio. Starch was added to the $\mathrm{Zn}\left(\mathrm{NO}_{3}\right)_{2}$ solution to a final concentration of $0.5 \%$, while the $\mathrm{NaOH}$ solution was heated to $70{ }^{\circ} \mathrm{C}$ (Fig. 1). The zinc nitrate/ starch solution was then added dropwise into the base over 30 minutes, followed by rapid stirring for $2 \mathrm{~h}$. The sample was then centrifuged and washed thrice with water and once with ethanol. The final product was collected by oven-drying the centrifuged pellet overnight at $60{ }^{\circ} \mathrm{C} .{ }^{28}$

Synthesis of rod shaped ZnO nanoparticles (RZNP). Solutions of $\mathrm{Zn}\left(\mathrm{NO}_{3}\right)_{2}$ and $\mathrm{NaOH}$ were made separately in distilled water in a $1: 2$ molar ratio. The $\mathrm{Zn}^{2+}$ solution was mixed with a CTAC solution, and the $\mathrm{OH}^{-}$solution was added into it at once (Fig. 1). The mixture was stirred rapidly at room temperature overnight, following which the sample was centrifuged and washed thrice with water and once with ethanol. The final product was collected by oven-drying the centrifuged pellet overnight at $60{ }^{\circ} \mathrm{C}^{29}$

Preparation of curcumin-loaded $\mathrm{ZnO}$ nanocomposites. A $2 \mathrm{mg} \mathrm{mL}{ }^{-1}$ stock solution of curcumin in acetone was prepared, while $10 \mathrm{mg}$ of $\mathrm{ZnO}$ nanoparticles (ZNPs) were dissolved in $1 \mathrm{~mL}$ acetone. The curcumin solution was then added to the $\mathrm{ZnO}$ solution. This mixture was stirred for 24 hours to complete the grafting/surface adsorption of curcumin to $\mathrm{ZnO}$ and to thus form the respective $\mathrm{ZnO}$-curcumin nanocomposite (ZNP-C). The resultant suspension was centrifuged at $6000 \mathrm{rpm}$ and washed thrice with distilled water and dried under vacuum. This method was followed for each different morphology of $\mathrm{ZnO}$ nanoparticle to form five different forms of ZNP-Cs.

\section{Characterization of curcumin-loaded nanoparticles}

Morphological analysis. The morphologies of ZNPs synthesized using the methods set out above were evaluated using field-emission scanning electron microscopy (SEM; Hitachi SU6600 setup). All samples were subjected to gold sputtering prior to analysis.

Chemical properties. Fourier-transform infrared (FT-IR) spectroscopic analysis was performed in order to confirm curcumin loading onto the surface of the various ZNPs. All spectra were obtained over the $4000-500 \mathrm{~cm}^{-1}$ region with 32 scans per measurement at a resolution of $4 \mathrm{~cm}^{-1}$ using a Bruker Vertex 80 Fourier transform infrared spectrophotometer (Bruker, USA). The spectrophotometer was equipped with a $\mathrm{L}$-alanine doped triglycine sulfate (DLaTGS) detector and MIRacle singlereflection horizontal attenuated total reflectance (ATR) accessory (PIKE Technologies, USA) working at room temperature.

Physical properties. Powder X-ray diffractometry was carried out using a Bruker Focus D8 machine $(\mathrm{Cu} \mathrm{K} \alpha$ radiation $\lambda=$ $0.1540562)$ at a scan rate of $10^{\circ} \mathrm{min}^{-1}$. Bruker DIFFRAC.SUITE EVA was used for all analyses.

The thermal stability of both ZNPs and ZNP-Cs was determined by thermogravimetric analysis (TGA; STD Q600 setup) over a temperature range of 25 to $1000{ }^{\circ} \mathrm{C}$ at a ramp of $10{ }^{\circ} \mathrm{C} \mathrm{min}^{-1}$ in a nitrogen medium.

\section{Assessment of curcumin loading}

A standard series of curcumin in acetone $\left(1-8 \mu \mathrm{g} \mathrm{mL}^{-1} / 1-8\right.$ $\mathrm{ppm})$ was made and intensity values at a $\lambda_{\max }$ of $419 \mathrm{~nm}$ collected. This was used for the construction of a calibration plot for the purpose of curcumin quantification.

$10 \mathrm{mg}$ of each ZNP-C sample was first resuspended in acidified acetone $(1 \mathrm{M} \mathrm{HCl})$, then sonicated for 20 minutes at room temperature in order to encourage complete dissociation of curcumin from $\mathrm{ZnO}$. Aliquots of the resultant suspension were drawn in triplicate, diluted as appropriate in acetone and subjected to UV-vis spectrophotometry; absorbance data was collected at a $\lambda_{\max }$ of $419 \mathrm{~nm}$. Concentrations of previously ZnObound curcumin were calculated by use of the calibration plot. ${ }^{30}$

\section{Antibacterial study}

The antibacterial activities of ZNPs and ZNP-Cs were tested against three Gram-positive bacteria (Staphylococcus aureus (ATCC 25923), Staphylococcus epidermidis (clinical isolate), Bacillus cereus (ATCC 9027)) and one Gram-negative bacterium (Escherichia coli (ATCC 35218)) using well- and drop diffusion methods. The well diffusion method was performed as described by Ratnasooriya et al. with slight modifications. ${ }^{31-33}$ Briefly, the organisms were subcultured on Mueller-Hinton agar, and a lawn culture prepared by spreading a fresh $100 \mu \mathrm{L}$ bacterial solution (having $10^{5} \mathrm{CFU} \mathrm{mL}^{-1}$ (complying with McFarland 0.5)) of each test organism on Mueller-Hinton agar plates. A $50 \mu \mathrm{L}$ aliquot of briefly-sonicated nanoparticle suspension $\left(5 \mathrm{mg} \mathrm{mL}^{-1}\right)$ was poured into the prepared wells ( $6 \mathrm{~mm}$ diameter). For drop diffusion, the same solutions were added as $10 \mu \mathrm{L}$ drops onto fresh agar surfaces in the same positions as in the well diffusion assay, in place of cutting wells.

In both cases, overnight incubation at $37^{\circ} \mathrm{C}$ followed, after which the different zones of inhibition were measured. Distilled water was used as the negative control, while gentamicin was used as the positive control throughout. ${ }^{34}$

\section{Assessment of anticancer activity and cytotoxicity}

Culturing rhabdomyosarcoma cells. Rhabdomyosarcoma (RD) cells were cultured in T25 culture flasks (NuncWiesbaden Germany), in MEM with 1 M HEPES, containing $10 \%$ FBS and $3 \%$ L-glutamine along with $7.7 \%$ sodium bicarbonate. Cultures were maintained at $37{ }^{\circ} \mathrm{C}$ and sub-cultured twice or thrice weekly. Cells were harvested on reaching $75-85 \%$ confluence using $0.25 \%$ trypsin, then seeded into 96 -well plates at a cell density of $1 \times 10^{5}$ cells per well.

Anticancer assay. Initially, the five ZNPs, ZNP-Cs and pure curcumin were dissolved separately in fresh culture media and added to the 96-well plate in triplicate, spanning a concentration series of $10-100 \mu \mathrm{g} \mathrm{mL} \mathrm{L}^{-1}$ each, alongside a positive control (25 mM cycloheximide) and $300 \mu \mathrm{L}$ media was used as the negative control. The final volume of each well was adjusted to $300 \mu \mathrm{L}$ with growth media. In order to determine $\mathrm{EC}_{50}$, the above procedure was repeated (for all ZNPs, ZNP-Cs and pure 
curcumin) with concentrations adjusted as appropriate. In all cases, the cells were incubated at $37{ }^{\circ} \mathrm{C}$ for 24 hours prior to measuring cell death.

The anticancer effect of ZNPs, ZNP-Cs and pure curcumin was assayed using the standard MTT (3-(4,5-dimethyl thiazol-2yl)-2,5diphenyl tetrazolium bromide) assay. Briefly, the wells were carefully emptied and filled with $100 \mu \mathrm{L}$ MTT ( $5 \mathrm{mg} \mathrm{mL}^{-1}$ in PBS). The cells were then incubated at $37^{\circ} \mathrm{C}$ for 4 hours and the excess MTT reagent was carefully removed without disturbing formazan crystals. The formazan crystals were then dissolved in acidified iso-propanol $(0.05 \mathrm{HCl}$ in IPA; $100 \mu \mathrm{L})$ by constant agitation on a reciprocating orbital shaker. Acidified isopropyl alcohol was used as the blank. Absorbance data was collected at a wavelength of $570 \mathrm{~nm}$ using a UV-vis plate reader, and cell viability calculated via the following equation (where $A$ is absorbance intensity) ${ }^{35}$

$$
\text { Cell viability }=\frac{A(\text { sample })-A(\text { blank })}{A(\text { positive control })-A(\text { blank })} \times 100 \%
$$

\section{Cytotoxicity study}

To determine the cytotoxic activity of the nanocomposites, the growth inhibition of HEK293 cells (Human embryonic kidney cells, ATCC CRL-1573) was measured using the resazurin dye reduction test. Briefly, a final concentration of $25 \mu \mathrm{g} \mathrm{mL}^{-1}$ resazurin was added into the cell culture, and fluorescence analyzed at ex.: 530/10 nm and em.: 590/10 nm (F560/590) after incubation at $37{ }^{\circ} \mathrm{C}$ and $5 \% \mathrm{CO}_{2}$ for $3 \mathrm{~h}$. A concentration gradient from $100 \mu \mathrm{g} \mathrm{mL}^{-1}$ to $0.2 \mu \mathrm{g} \mathrm{mL}^{-1}$ of each material (ZNPs, ZNP-Cs and pure curcumin) was used in this cytotoxicity assay. The percentage growth inhibition and $\mathrm{CC}_{50}$ (concentration at $50 \%$ cytotoxicity) were calculated for each sample in triplicate. A negative control of pure culture media, and a positive control in the form of tamoxifen were also utilized. ${ }^{36}$

\section{Results and discussion}

\section{Morphological analysis}

The successful synthesis of a variety of different morphologies of $\mathrm{ZnO}$ nanoparticles was confirmed by the scanning electron microscope (SEM) images given in Fig. 2. Spherical particles (Fig. 2A) were observed to have a diameter within the $40-100 \mathrm{~nm}$ range, with some slight ovoid features.

Rod-shaped nanoparticles with a length of between 600 and $900 \mathrm{~nm}$ and a width of $<300 \mathrm{~nm}$ are shown in Fig. 1B. Javelinshaped nanoparticles (Fig. 2C) with a length of between 300 and $600 \mathrm{~nm}$ and widths of $<300 \mathrm{~nm}$ were also successfully synthesized, with the main difference between these and the rodshaped nanoparticles being the more ovoid, pellet-like shape of the former. Fig. 2D and E show the two nanoflowers with shortand long 'petals' respectively. The short petal nanoflowers are, as particles, larger than the long petal nanoflowers, with the former having particle diameters (petal tip to petal tip) of between 2 and $4 \mu \mathrm{m}$, while the latter having particle diameters of approx. $500 \mathrm{~nm}$. Nevertheless, both types of nanoflowers have
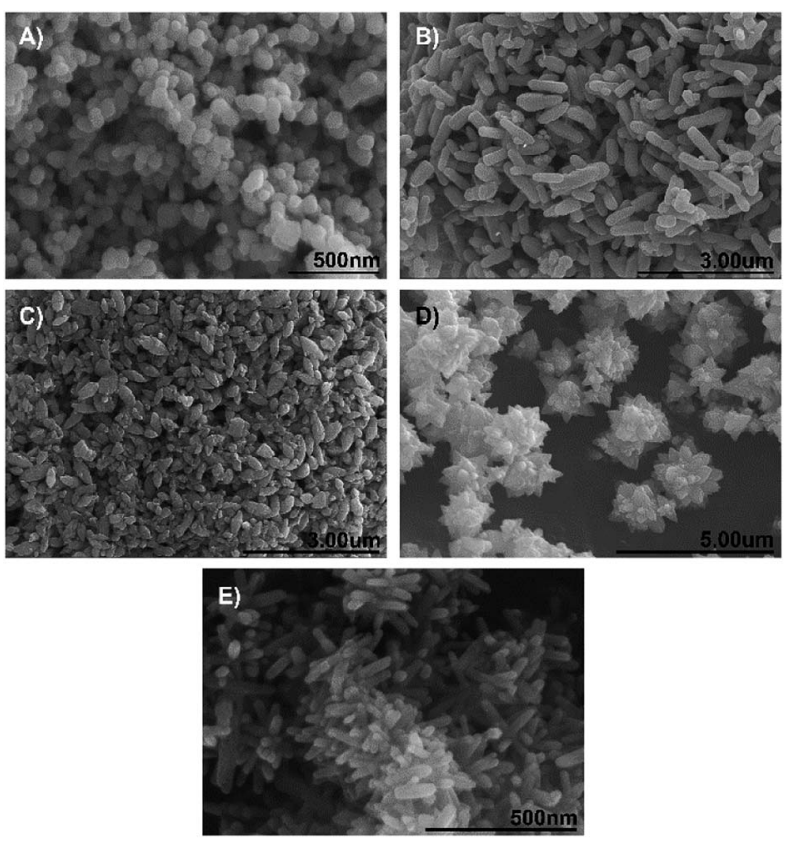

Fig. 2 Scanning electron microscope images of different morphologies of ZnO nanoparticles: (A) Spherical nanoparticles (SZNPs), (B) rod-shaped nanoparticles (RZNPs), (C) javelin-shaped nanoparticles (JZNPs), (D) short petal nanoflowers (SPZNPs) and (E) long petal nanoflowers (LPZNPs). Note the central nexus/axis from which rodlike 'petals' emanate from in the latter.

protrusions (here referred to as 'petals') that emanate from a central point, which have dimensions in the nanoscale.

Various methods have been used to prepare zinc oxide nanoparticles such as hydrothermal, ${ }^{37-39}$ solvothermal, ${ }^{40,41}$ microemulsion, ${ }^{42}$ sol-gel ${ }^{\mathbf{4 3 , 4 4}}$ and thermal decomposition of precursors. ${ }^{45,46}$ The shape and size of ZNPs are dependent on various factors affecting kinetics, including concentration of reactant, type of base, $\mathrm{pH}$, temperature, stir speed and surfactant. The particles formed may be nanorods, ${ }^{47}$ nanoplates, ${ }^{48}$ nanospheres, ${ }^{49}$ nanoboxes, hexagonal, tripods, ${ }^{50}$ tetrapods, ${ }^{51}$ nanowires, ${ }^{52}$ nanotubes, nanorings, ${ }^{53}$ nanocages, and nanoflowers ${ }^{54}$ ranging from a few nanometres to around $900 \mathrm{~nm}$. This study employed both solvothermal and sol-gel methods in a simpler, one-pot reaction attempted by others such as Tong et al. (2013), ${ }^{53}$ using only $\mathrm{NaOH}$ at different concentrations as a precipitator, and CTAC, PEG and starch as structure-directing surfactants. PEG and starch likely played the role of organic templates for the formation of the two ZNP nanoflowers. ${ }^{55,56}$ In general, the $\mathrm{OH}$ groups provided by a base such as $\mathrm{NaOH}$ leads to the formation of the $\left[\mathrm{Zn}(\mathrm{OH})_{4}\right]^{2-}$ complex, the crucial growth unit of ZNPs. This can then be induced to grow preferentially along one or more crystalline planes through the modulation of the kinetic factors noted above, particularly the Zn-base ratio, and the type and concentration of surfactant, which affect the rate of both nucleation and subsequent growth of $\mathrm{ZnO}$ nanostructures. ${ }^{56}$

\section{Chemical characterization}

FTIR spectra of pure $\mathrm{ZnO}$, pure curcumin and $\mathrm{ZNP}-\mathrm{C}$ nanocomposites (RZNP-C, SZNP-C, LPZNP-C, SPZNP-C and JZNP- 
C) are shown in Fig. 3. FTIR of all ZNP samples clearly showed a broad peak between 3600 and $3050 \mathrm{~cm}^{-1}$. The FTIR spectrum of the ZnO nanoparticles, curcumin, and ZNP-Cs nanocomposites were scanned in the range of $4000-500 \mathrm{~cm}^{-1}$. The nanocomposite showed the expected $\mathrm{Zn}-\mathrm{O}$ stretching vibrations at $677 \mathrm{~cm}^{-1}$, as well as the bands caused by interatomic vibrations of metal oxides at 802,833 , and $881 \mathrm{~cm}^{-1}$. The benzoate trans-C-H vibration was also observed at $962 \mathrm{~cm}^{-1}$. The peaks at 1197 and $3346 \mathrm{~cm}^{-1}$ are likely caused by $\mathrm{O}-\mathrm{H}$ deformation and stretching, respectively, on account of the moisture adsorbed on the NP surface. ${ }^{29}$ The peak at $1274 \mathrm{~cm}^{-1}$ was assigned to the enol $\mathrm{C}-\mathrm{O}$, and that at $1508 \mathrm{~cm}^{-1}$ was likely due to $\mathrm{C}=\mathrm{O}$. Symmetric stretching vibrations of the aromatic $\mathrm{C}=\mathrm{C}$ bonds produces a band at $1600 \mathrm{~cm}^{-1}$, while the peak at $3014 \mathrm{~cm}^{-1}$ pertains to $\mathrm{C}-\mathrm{H}$ stretching, and the broad peak at $3512 \mathrm{~cm}^{-1}$ is the characteristic $\mathrm{O}-\mathrm{H}$ stretch.

Relative to curcumin, the reduction in intensity of the band at $962 \mathrm{~cm}^{-1}$, and shifting of the $\mathrm{ZnO}$ band at 881 to $871 \mathrm{~cm}^{-1}$ in the nanocomposite could indicate chelation of carbonyl or hydroxyl groups of curcumin with zinc. ${ }^{57}$ Hence, the FTIR spectra serve to confirm the formation of the metal-curcumin complex.

\section{Physical characterization}

The XRD patterns of bare ZNPs are shown in Fig. 4A, with the results matching JCPDS card no. 00-0361451, showing the presence of crystalline $\mathrm{ZnO}$ in its customary wurtzite phase. The patterns exhibit characteristic $2 \theta /$ basal plane pairs of $31.78^{\circ} /$ (100), $34.46^{\circ} /(002), 36.29^{\circ} /(101), 47.63^{\circ} /(102), 56.70^{\circ} /(110)$, $62.95^{\circ} /(103), 68.04^{\circ} /(200)$ and $69.07^{\circ} /(201)$. No great differences are apparent between the various ZNP morphologies, but the lack of peaks other than those regarded as characteristic points to a high degree of sample purity. Fig. 4B shows XRD patterns obtained for the loaded ZNP-Cs, compared with that of pure curcumin. The latter shows good crystallinity by the presence of

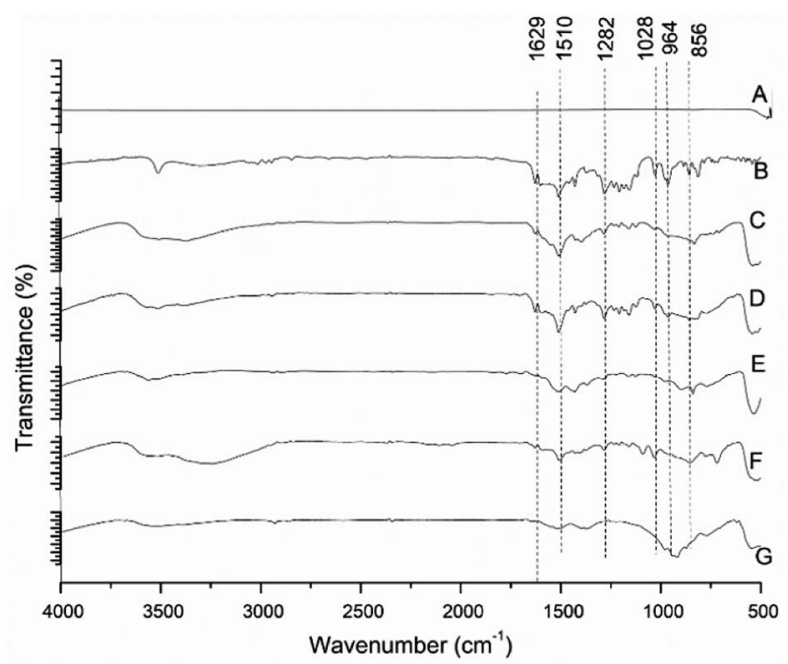

Fig. 3 FT-IR spectra of different morphologies of $\mathrm{ZnO}$ nanoparticles. (A) Pure ZnO, (B) pure curcumin, (C) JZNP-C, (D) LPZNP-C, (E) RZNP$C$, (F) SPZNP-C and (G) SZNP-C. peaks between $2 \theta$ values of 10 and $30^{\circ},{ }^{58}$ two of which are present in the patterns of the nanocomposites $\left(21.55^{\circ}\right.$ and $\left.23.88^{\circ}\right)^{59,60}$ albeit at reduced intensities. This reduction in intensity and the absence of other characteristic curcumin peaks (such as that at $17.44^{\circ}$ ) may point to the formation of inclusion complexes of curcumin within the surface of their host ZNPs, exposing only a select number of basal planes.

Thermogravimetric analysis (TGA) of ZNP-C nanocomposites (RZNP-C, SZNP-C, LPZNP-C, SPZNP-C and JZNPC) was carried out to approximate curcumin loading (Fig. 5). Loss of water occurred at approximately $110{ }^{\circ} \mathrm{C}$, and all thermograms showed characteristic curcumin degradation (to varying degrees) between 280 and $420{ }^{\circ} \mathrm{C}$. Loading of curcumin onto ZNPs was calculated approximately by subtracting the mass loss of the bare nanoparticle from that of the loaded one. These results are presented in Table 1 with the result of postdigestion amount of curcumin. The mean of both studies was taken as the loaded percentage of curcumin.

Results of both the TGA and post-digestion of nanoparticles give a similar pattern of curcumin loading on the nanoparticles. The greatest percentage of curcumin-containing nanocomposites was observed in LPZNP-C, interpreted as being indicative of the highest curcumin loading of all synthesized nanocomposites. This was to be expected due to the comparatively high surface area lent to this particle by the presence of long needle-like 'petals', and in particular the deep crevices between them. Though the sphere has the highest surface areato-volume ratio, the percentage of loaded curcumin is comparatively modest, likely due to the leaking of trapped curcumin during washing. The percentage mass loss of curcumin was observed to be the lowest in SPZNP-C, while lowest post-digestion curcumin percentage was observed in SZNP-C. This is most likely due to the comparatively low surface area-tovolume ratio.

Comparison of Fig. 5A and B also provides an interesting insight: whereas the order of mass loss amongst bare ZNPs were in the order SPZNP $>$ JZNP $>$ LPZNP $>$ RZNP $>$ SZNP, the.mass loss amongst loaded nanocomposites is changed to LPZNP-C $>$ JZNP-C $>$ SPZNP-C $>$ RZNP-C $>$ SZNP-C. This is most likely due to the higher curcumin loading (see Table 1 ) in the long petal nanoflowers compared to the lower loading in javelin- and small petal forms, resulting in greater mass loss in the composite containing the highest amount of loaded curcumin, and the other two following in order of loaded curcumin.

\section{Antibacterial assay}

The degree of antibacterial activity of nanoparticles is usually size-dependent, being an inversely proportional relationship. Therefore, nanoscale $\mathrm{ZnO}$ was expected to show better antibacterial activity than bulk $\mathrm{ZnO} .{ }^{61,62}$ Apart from the size, activity also depends on shape. In this work, oblong particles showed higher activity than spherical ones.

The antibacterial activities of $\mathrm{ZNP}-$ and $\mathrm{ZNP}-\mathrm{C}$ nanocomposites (RZNP-C, SZNP-C, LPZNP-C, SPZNP-C and JZNPC) were tested by the disc- and well diffusion agar methods on Gram-positive strains (S. aureus, B. cereus and S. epidermidis) as 
A)

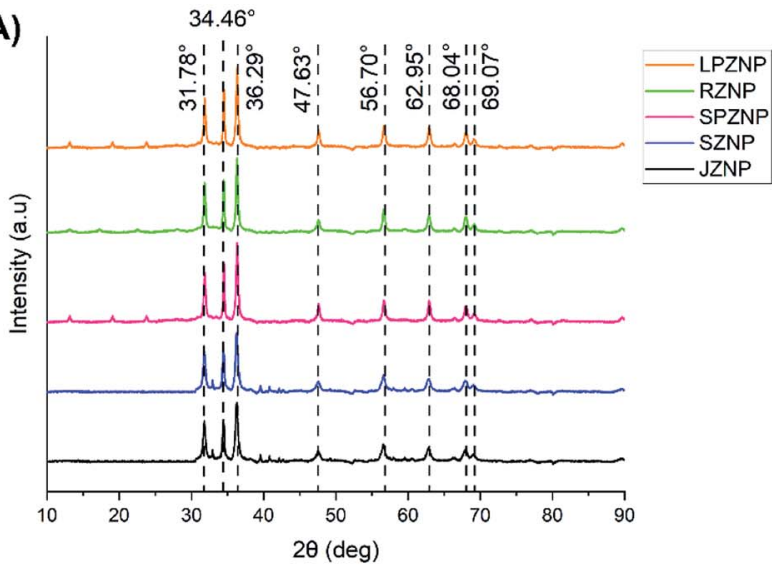

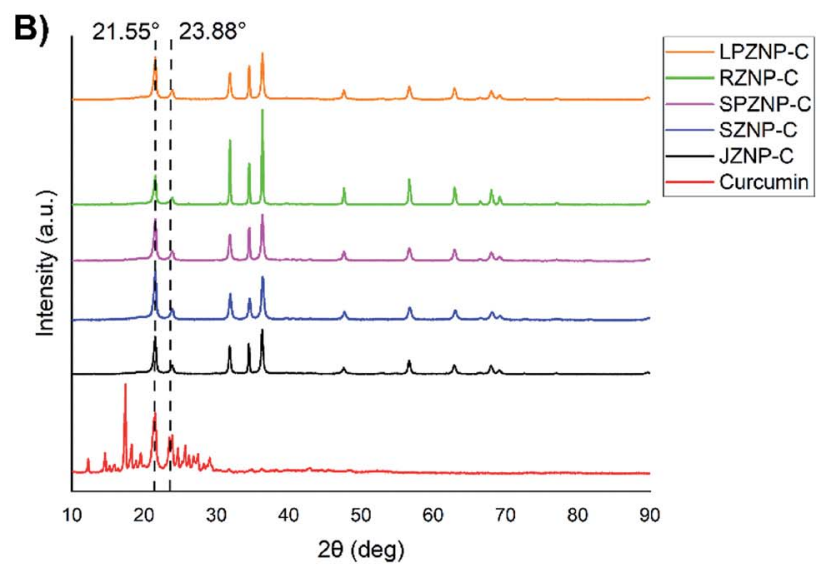

Fig. 4 XRD patterns of: (A) bare ZNPs and (B) curcumin and ZNP-Cs.

well as Gram-negative strains (E. coli) accordingly. The size of the inhibition zones (Fig. 6) appeared to vary dependent upon the type of bacteria and the type of $\mathrm{ZnO} / \mathrm{ZnO}$-curcumin nanocomposites; E. coli appeared to be the least susceptible to the antibacterial activity of all nanocomposites tested, most likely due to the thicker cell membrane. Tyagi et al. $2015,{ }^{64}$ in their work with curcumin I observed $E$. coli to be among the bacteria least susceptible to it. ${ }^{6}$ Nevertheless, all ZNPs and ZNP-Cs showed some antibacterial activity against both the Grampositive and Gram-negative strains. In the drop diffusion assay, SZNP-C showed the most promising activity against $S$. epidermidis $(22.2 \pm 0.3 \mathrm{~mm})$, while RZNP-C had the most potency against $B$. cereus $(20.2 \pm 0.8 \mathrm{~mm})$, S. aureus $(17.7 \pm 0.1)$, and $E$. coli $(10.7 \pm 0.4 \mathrm{~mm})$. The results for $S$. aureus are consistent with those obtained by others, wherein it is one of the most susceptible to curcumin's antibacterial activity. ${ }^{63}$ The inhibition zones for these curcumin-loaded $\mathrm{ZnO}$ nanocomposites were consistently larger than their bare counterparts or pure curcumin, revealing an additive effect between the $\mathrm{ZnO}$ and curcumin components. This pattern of ZNP-Cs having a higher antibacterial effect than the correspondingly shaped
ZNPs holds true across all shapes of the nanocomposites. These general trends hold true for the well diffusion assay as well, albeit at a lower magnitude, likely due to the generally slower diffusion of nanoparticles through the agar bulk as opposed to lateral diffusion on its surface.

The antibacterial action of curcumin has been shown to be exerted through a number of different mechanisms. It has been shown to be capable of permeabilizing the bacterial membrane regardless of Gram status, ${ }^{64}$ leading to lysis. This may take place due to curcumin's demonstrated ability to bind to peptidoglycans. ${ }^{63}$ Curcumin has also been demonstrated to interact with the prokaryotic FtsZ protein in vitro to inhibit assembly of its protofillaments, interfering with the formation of the $\mathrm{z}$ ring, thereby destabilizing the bacteria replication process. ${ }^{65}$ Other antibacterial mechanisms include: inhibition of bacterial quorum sensing (affecting both biofilm formation and virulence; possibly through inhibition of sortaseA) and the inhibition of bacterial DNA damage repair process (contributing to bacteriostatic effects) (Table 2). ${ }^{66}$

Several reports suggest that the action of $\mathrm{ZnO}$ on bacterial species is due to creation of reactive oxygen species (ROS) and
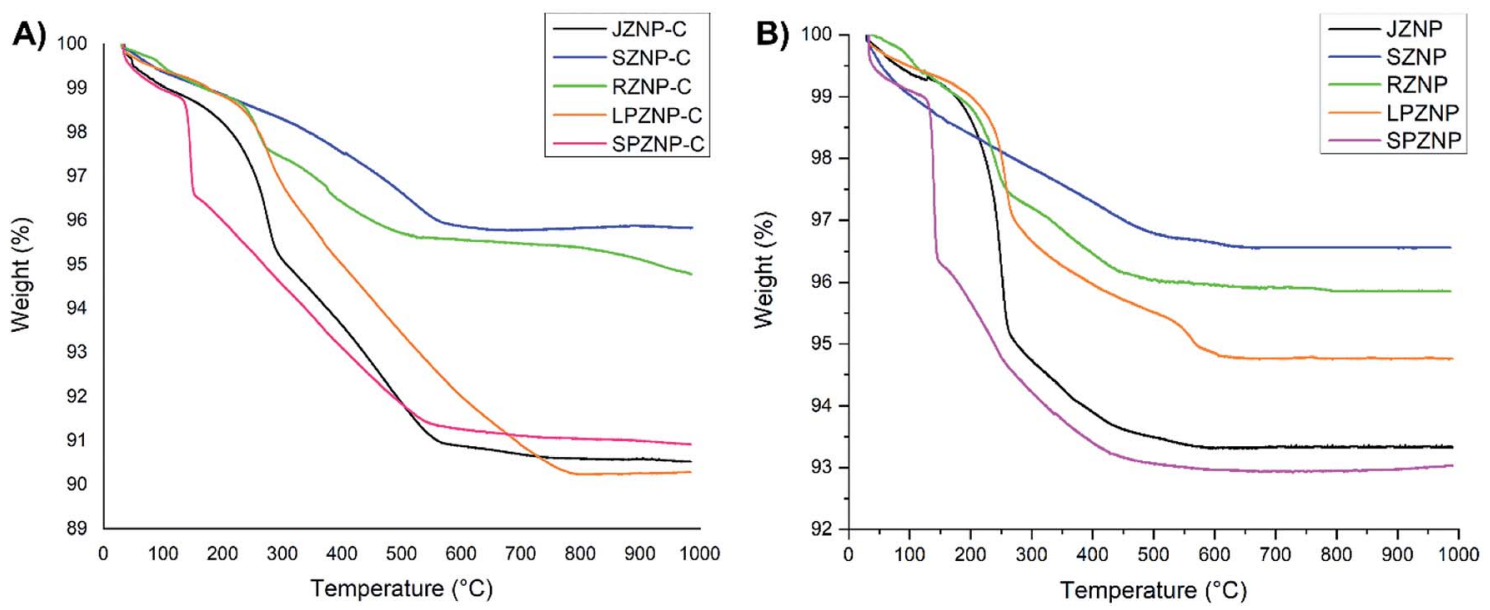

Fig. 5 Thermograms of different morphologies of $\mathrm{ZnO}$ nanocomposites. (A) With no loaded curcumin, (B) with loaded curcumin. 
Table 1 Curcumin loading of zinc-curcumin nanocomposites as assayed by TGA and post-digestion of nanoparticle

$\%$ Curcumin loaded $(\mathrm{w} / \mathrm{w})$

\begin{tabular}{llc} 
Nanoparticle shape & TGA (mass loss) & $\begin{array}{l}\text { Post-digestion } \\
\text { (UV-vis) }\end{array}$ \\
\hline Rod & 4.36 & 3.93 \\
Sphere & 4.20 & 5.72 \\
Long petal & 9.03 & 10.25 \\
Short petal & 4.58 & 3.14 \\
Javelin & 9.00 & 8.37
\end{tabular}

release of zinc ions. Generated ROS (i.e. hydrogen peroxide $\left(\mathrm{H}_{2} \mathrm{O}_{2}\right), \mathrm{OH}^{-}$(hydroxyl radicals), $\mathrm{O}_{2}{ }^{2-}$ (peroxide)) and zinc ions from $\mathrm{ZnO}$ nanoparticles bind to the negative surface of the cell membrane, leading to disruption of the cells, followed by leakage of cellular material to cause cell death., ${ }^{4,21,67}$ Additive effects of curcumin with different antibiotics such as ampicillin, oxacillin, and norfloxacin against methicillin-resistant $S$. aureus have been previously reported ${ }^{68}$ The MIC of ZNPs against $S$. aureus was reported to be $1 \mathrm{mg} \mathrm{mL}{ }^{-1}{ }^{69} \mathrm{ZnO}$ combined with ciprofloxacin or gentamicin has also been demonstrated to be effective against $S$. aureus. ${ }^{70,71}$ A recent study using nanocurcumin, ZNPs, and curcumin/ZNP nanocomposites against $S$. aureus, B. subtilis, E. coli, and P. aeruginosa showed the nanocomposite to have higher efficacy than the pristine ZNPs and nanocurcumin on their own. ${ }^{57}$ The antibacterial activity of curcumin-loaded $\mathrm{ZnO}$ nanocomposites were significantly higher compare to the pure curcumin and $\mathrm{ZnO}$
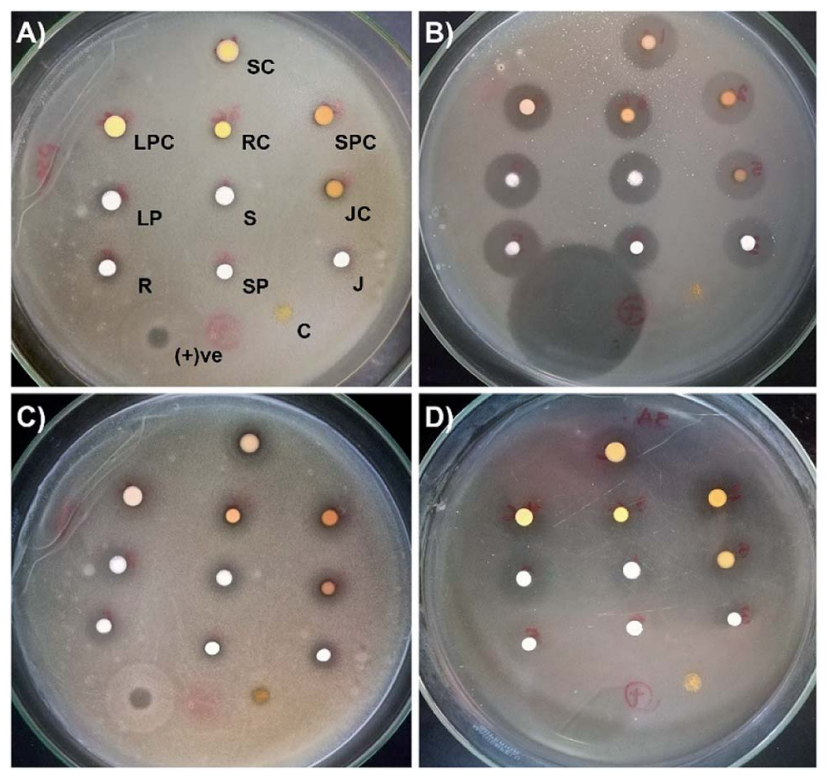

Fig. 6 Culture plates utilized for the antibacterial assay. (A) E. coli, (B) S. epidermidis, (C) S. aureus, (D) B. cereus. Positions of all treatment agents were kept the same on each plate $(\mathrm{SC}-$ spherical + curcumin, LPC-long petal + curcumin, RC-rod + curcumin, SPC-short petal + curcumin, JC-javelin + curcumin, LP-long petal, S-spherical, Rrod, SP-short petal, J-javelin, C-curcumin).
NPs. From this, it is reasonable to conclude that there exists additive effect between the $\mathrm{ZnO}$ and curcumin components in the composites studied herein as well, and that this combination can be used as a potent antibacterial agent for various purposes including medical. ${ }^{68,70}$ The combined effects of ZNPCs on bacteria are outlined in Fig. 7.

\section{Anticancer assay}

The anticancer activity of ZnO-curcumin nanocomposites was assessed against rhabdomyosarcoma (RD) cells, a cancer that affects children and adolescents in particular, ${ }^{72,73}$ and has previously been used in similar studies. ${ }^{74,75}$

The results of this assessment (performed by use of the MTT assay) are summarized in Fig. 8A, 9 and S2 in the ESI. $\dagger$ Pure curcumin resulted in $50 \%$ cell viability in rhabdomyosarcoma (RD) cells after treatment with a $12 \mu \mathrm{g} \mathrm{mL}{ }^{-1}$ solution. RZNP, SZNP, LPZNP, SPZNP and JZNP showed $50 \%$ cell death at concentrations of 7.8, 9.6, 2.9, 15.0 and $11.0 \mu \mathrm{g} \mathrm{mL} \mathrm{mL}^{-1}$ respectively. In contrast, $\mathrm{ZnO}$-curcumin nanocomposites displayed a general tendency to have lower $\mathrm{EC}_{50}$ values. As such, RZNP-C, SZNP-C, LPZNP-C, SPZNP-C and JZNP-C produced $50 \%$ cell death at concentrations of $2.4,7.6,13.0,8.9$ and $0.8 \mu \mathrm{g} \mathrm{mL}^{-1}$ respectively (Fig. 8).

During this assay, the same mass of bare nanoparticles and curcumin-loaded nanoparticles were used in all cases. Thus, the weight percentage of $\mathrm{ZnO}$ in the assay of curcumin-loaded particles is lower than in the case of the bare particles, since a proportion of the curcumin-containing sample consists of curcumin itself. The reduction of $\mathrm{ZnO}$ should logically lead to a concomitant decrease in anticancer toxicity had the composites had the same anticancer activity as the bare nanoparticles. However, the results show that the addition of even a small quantity of curcumin to this reduced $\mathrm{ZnO}$ mass leads to a sharp increase in anticancer activity, reflected by the decrease in $\mathrm{EC}_{50}$. The anticancer activity of pure curcumin lends support to this observation and previous literature that note the compound's activity against cancer cell lines..$^{55,56}$

Various in vitro studies have shown that curcumin induces apoptosis in oncogenic cells by inhibiting various intracellular transcription factors and secondary messengers such as NF-kB, AP-1, c-Jun, the JAK-STAT pathway, and various others. ${ }^{3,4,7}$

Curcumin is well-known for its potential to inhibit carcinogenesis induced by chemical carcinogens, at both initiation and progression stages in various preclinical studies. ${ }^{76}$ It is known to inhibit cytochrome P450 (CYP) enzyme mediated bioactivation of environmental carcinogens like benzo $[a]$ pyrene $(\mathrm{B}[a] \mathrm{P}){ }^{77}$ Curcumin is a competitive inhibitor of $\mathrm{B}[a] \mathrm{P}$ metabolism and thus depresses its bioactivation via CYP1A1. ${ }^{78}$ Curcumin also increases the levels of other endogenous antioxidants via the Nrf2 pathway to strengthen the body's defences against reactive oxygen species. ${ }^{4,7}$

According to the results obtained herein, the $\mathrm{ZnO}$ nanoparticle itself showed some anticancer properties. Several studies have demonstrated that ROS generation is a key cytotoxic mechanism of ZNPs. ROS (mainly superoxide, hydroxyl radicals and hydrogen peroxide) are constantly generated and 
Table 2 Results of the antibacterial assays (see Fig. 6) of different shapes of ZNPs, curcumin-loaded ZNPs and pure curcumin against pathogenic bacterial stains

\begin{tabular}{|c|c|c|c|c|c|c|c|c|}
\hline & \multicolumn{8}{|c|}{ Antimicrobial activity $\left(5 \mathrm{mg} \mathrm{mL} \mathrm{m}^{-1}\right)$ (mean inhibition zone diameter \pm standard error $\left.-\mathrm{mm}\right)$} \\
\hline & \multicolumn{2}{|l|}{ E. coli } & \multicolumn{2}{|c|}{ S. epidermidis } & \multicolumn{2}{|l|}{ S. aureus } & \multicolumn{2}{|l|}{ B. cereus } \\
\hline SZNP & $6.2 \pm 0.4$ & $8.6 \pm 0.5$ & $14.1 \pm 0.3$ & $18.6 \pm 0.5$ & $13.1 \pm 0.7$ & $14.6 \pm 0.6$ & $13.2 \pm 0.8$ & $14.1 \pm 1.0$ \\
\hline SZNP-C & $8.4 \pm 0.8$ & $10.2 \pm 0.3$ & $19.1 \pm 0.1$ & $22.2 \pm 0.3$ & $15.4 \pm 1.1$ & $17.0 \pm 0.4$ & $17.4 \pm 0.7$ & $19.6 \pm 1.5$ \\
\hline RZNP & $8.4 \pm 0.1$ & $9.7 \pm 0.2$ & $14.4 \pm 0.4$ & $17.4 \pm 0.2$ & $12.5 \pm 0.3$ & $14.3 \pm 0.6$ & $15.4 \pm 0.8$ & $18.9 \pm 0.5$ \\
\hline RZNP-C & $10.1 \pm 0.5$ & $10.7 \pm 0.4$ & $17.2 \pm 0.4$ & $20.0 \pm 0.8$ & $16.6 \pm 0.7$ & $17.7 \pm 0.1$ & $18.7 \pm 0.2$ & $20.2 \pm 0.6$ \\
\hline SPZNP & $7.8 \pm 0.6$ & $8.2 \pm 0.4$ & $14.1 \pm 1.1$ & $14.3 \pm 0.1$ & $13.0 \pm 0.6$ & $13.1 \pm 0.7$ & $11.4 \pm 0.6$ & $11.3 \pm 0.1$ \\
\hline SPZNP-C & $8.1 \pm 0.1$ & $8.9 \pm 1.2$ & $16.4 \pm 0.4$ & $17.7 \pm 0.2$ & $15.2 \pm 0.8$ & $15.9 \pm 0.4$ & $14.2 \pm 0.4$ & $13.5 \pm 0.6$ \\
\hline JZNP & $9.0 \pm 0.5$ & $10.3 \pm 0.7$ & $16.0 \pm 0.6$ & $16.7 \pm 0.5$ & $12.4 \pm 0.1$ & $15.0 \pm 0.8$ & $15.3 \pm 0.4$ & $16.0 \pm 0.5$ \\
\hline JZNP-C & $11.1 \pm 0.2$ & $10.5 \pm 0.6$ & $19.4 \pm 0.1$ & $20.9 \pm 0.8$ & $13.4 \pm 0.4$ & $15.5 \pm 0.8$ & $18.7 \pm 0.3$ & $19.3 \pm 0.2$ \\
\hline
\end{tabular}

eliminated in biological systems. It is well-known that ROS play important roles in a variety of normal biochemical functions and aberrant pathological processes. Elevated ROS accumulation that exceeds the level of the cellular antioxidant defence system causes oxidative stress in cells, which leads to the damage of cellular components, including lipids, proteins, and DNA. ${ }^{4,20,21,79}$ In addition, $\mathrm{Zn}^{2+}$ ions have also been shown to induce a cytotoxic effect in cancer cells, also by inducing oxidative stress. ${ }^{80}$ In the present study, ZNP-Cs showed the additive anticancer effect of both ZnO NP and curcumin, and therefore, it can be considered as a potential candidate or supplement for cancer chemotherapy.

\section{Cytotoxicity study}

In the cytotoxicity assay against the designated healthy Human Embryonic Kidney (HEK) cells, pure curcumin caused a 50\% drop in cell viability at a concentration of $88 \mu \mathrm{g} \mathrm{mL} \mathrm{m}^{-1}$. RZNP, SZNP, LPZNP, SPZNP and JZNP showed 50\% cell death at concentrations of $1.42,39,0.96,5.5$ and $1.5 \mu \mathrm{g} \mathrm{mL}{ }^{-1}$ respectively. In contrast, $\mathrm{ZnO}$-curcumin nanocomposites, displayed a general tendency to have higher $\mathrm{CC}_{50}$ values in this case. RZNP-C, SZNP-C, LPZNP-C, SPZNP-C and JZNP-C produced $50 \%$ cell death at concentrations of $1.9,48,2.4,20$ and $0.66 \mu \mathrm{g} \mathrm{mL} \mathrm{m}^{-1}$ respectively. This decrease in toxicity cannot be wholly attributed to the presence of curcumin,

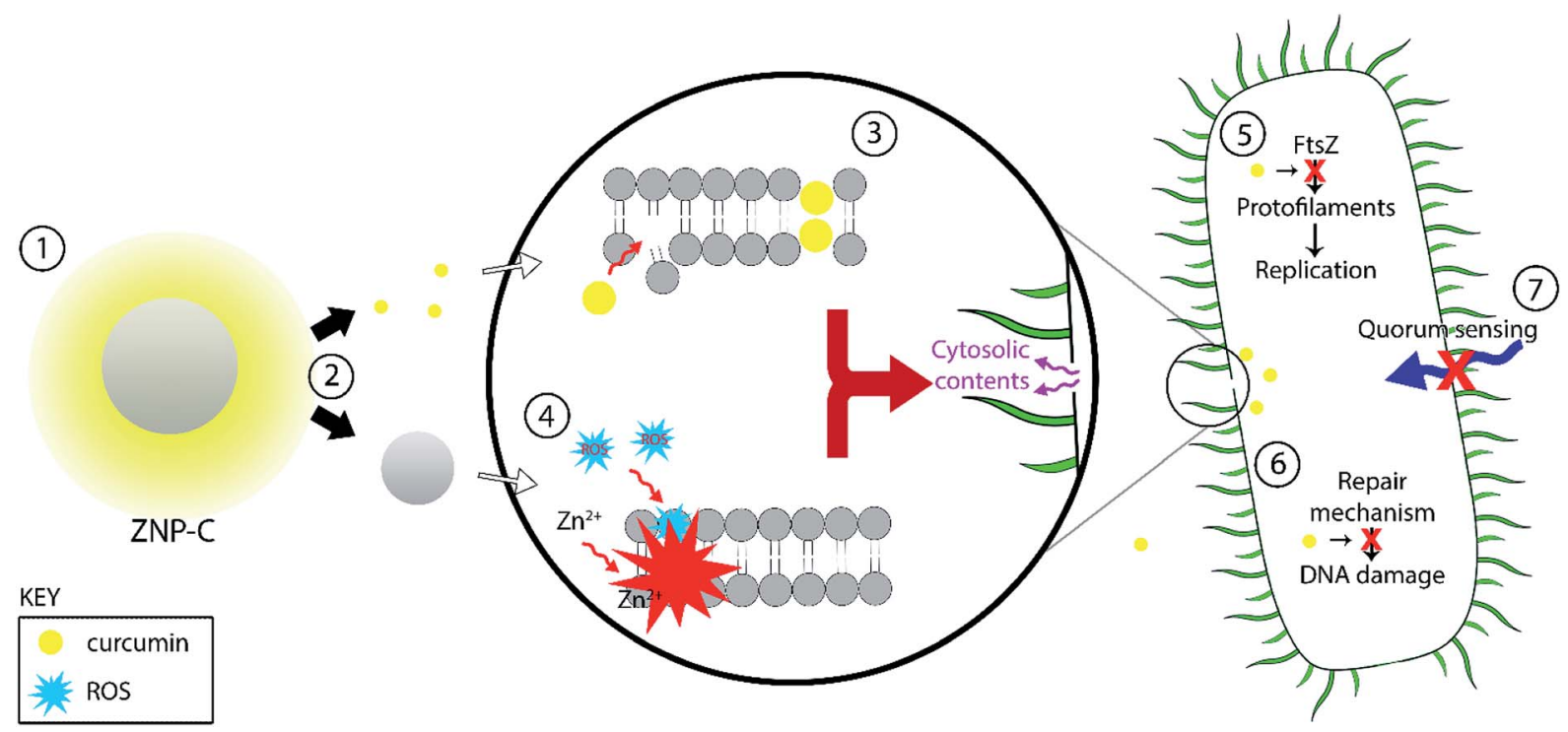

Fig. 7 The antibacterial mechanisms effected by curcumin. (1) Release of the curcumin from the ZnO-curcumin nanoparticle (ZNP-C) surface; (2) curcumin and ZNP exert their effects additively; (3) curcumin damages bacterial membrane, weakening peptidoglycan bilayer; (4) reactive oxygen species (ROS) and $\mathrm{Zn}^{2+}$ ions generated by the ZNPs damage the membrane; both (3) and (4) lead to membrane disruption and lysis. (5) Bacterial replication is slowed/halted; (6) DNA repair is inhibited; (7) quorum sensing interfered with. 


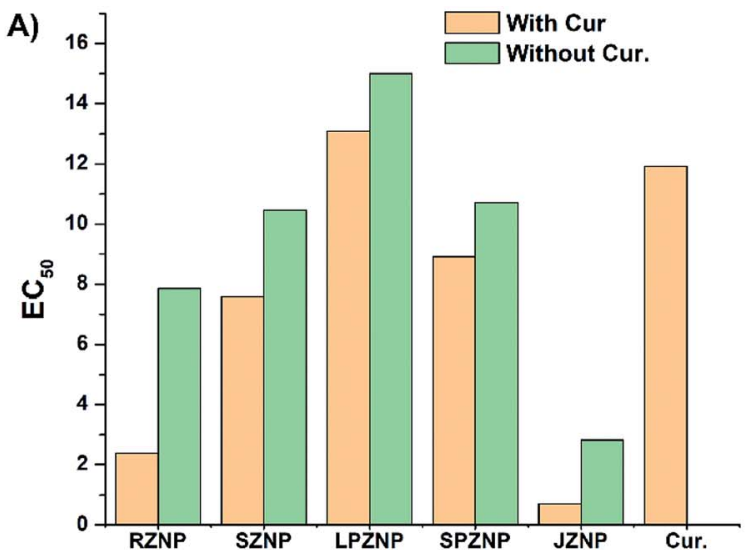

B)

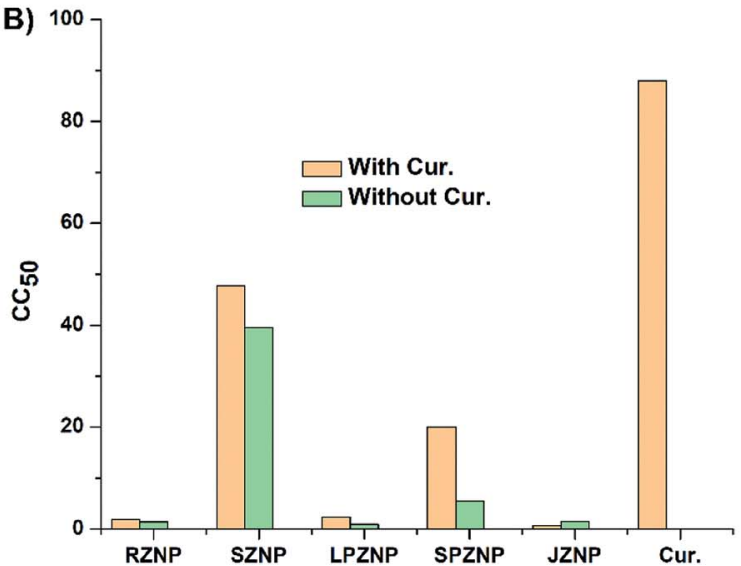

Fig. 8 (A) Calculated EC $_{50}$ values of different shapes of ZNP, curcuminloaded ZNPs and pure curcumin against rhabdomyosarcoma cells. (B) Calculated $\mathrm{CC}_{50}$ values of different shapes of ZNPs, curcumin-loaded ZNPs and pure curcumin against Human Embryonic Kidney (HEK) cells.

since as noted before the amount of $\mathrm{ZnO}$ in the sample is lower than in the case of the assay with bare nanoparticles. Nevertheless, it is interesting to note that the pure curcumin has a high $\mathrm{CC}_{50}$ against this healthy cell line (see Fig. 8B and S3 in the ESI $\dagger$ ).

The highest cytotoxicity against HEK cells was shown by JZNP-C, which rules it out as a potential anticancer agent in the form tested in this work. RZNP-C has the next-highest toxicity against the healthy cell line; its anticancer activity against RD cells is considerable, but due to its nonspecific toxicity, it must also be ruled out. The same holds true for LPZNP-C, whose $\mathrm{CC}_{50}$ against HEK cells is almost a six-fold increase over its $\mathrm{EC}_{50}$ against the cancer cells-a situation that is highly undesirable. In these cases, the high degree of toxicity can be attributed to the high aspect ratio of the $\mathrm{ZnO}$ structures.

The lowest cytotoxicity against HEK cells was exhibited by SPZNP-C and SZNP-C. Both of these have higher $\mathrm{CC}_{50}$ values against $\mathrm{HEK}$ cells than $\mathrm{EC}_{50}$ values against $\mathrm{RD}$ cells, with SPZNP-C having an approximately 2 -fold decrease, and SZNP-C having an approximately 6 -fold decrease in cytotoxicity against healthy cells compared to toxicity towards the cancer cell line. Given this, SZNP-C can be clearly identified as having the best/ optimal balance between toxicity against healthy cells and anticancer activity against the RD cell line.
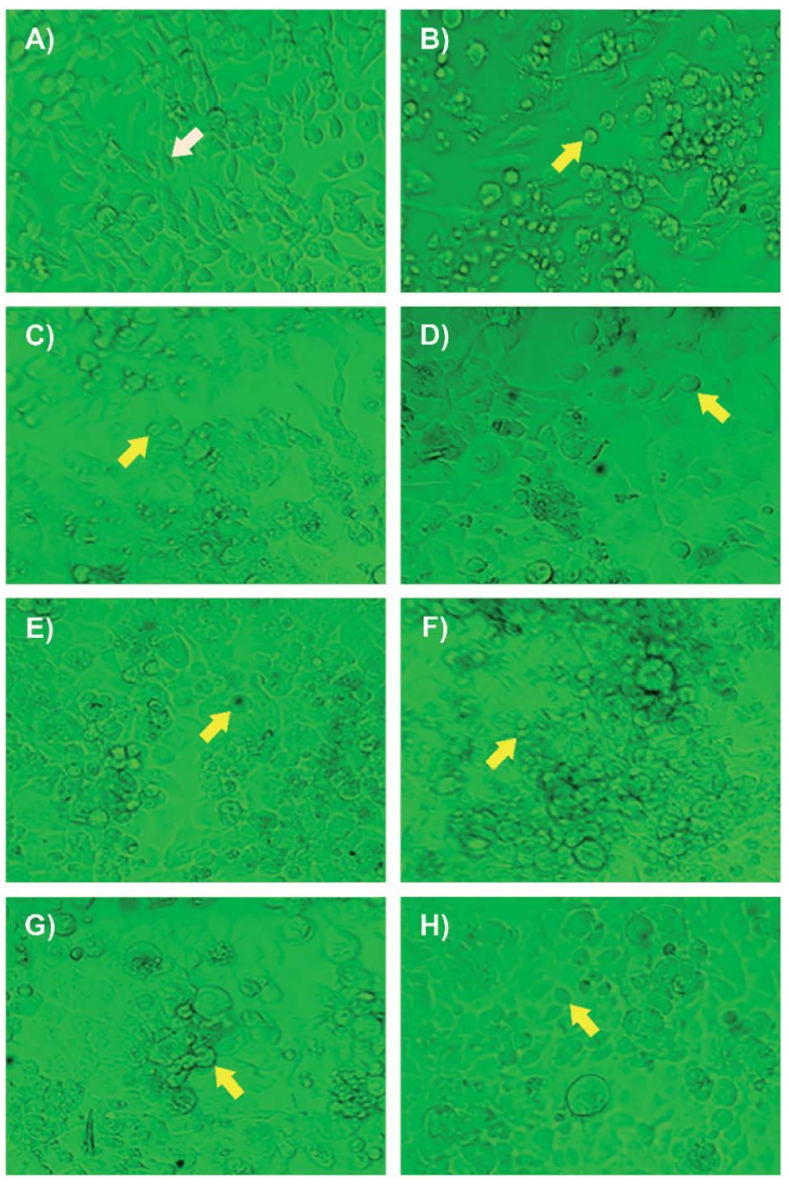

Fig. 9 Morphological changes induced by cell death in RD cells, observed under inverted light microscope following $24 \mathrm{~h}$-exposure to different types of curcumin loaded zinc oxide nanocomposites. (A) Negative control, (B) positive control, (C) RZNP-C, (D) SZNP-C, (E) SPZNP-C, (F) JZNP-C, (G) LPZNP-C and (H) pure curcumin. Whiteand yellow arrowheads denoted healthy and dead cells respectively.

\section{Conclusions}

In this study, we investigated the potential of curcumin-loaded ZnO nanocomposites/nanoparticles (ZNP-Cs) as efficient antibacterial and anticancer agents. Upon successful loading of curcumin onto $\mathrm{ZnO}$ nanoparticles, an additive activity between the two components resulted in markedly improved antibacterial- and anticancer activities. Moreover, the spherical (SZNP-C) nanocomposite showed good antibacterial/ anticancer activity with considerably less cytotoxic activity than other ZNP-Cs. SZNP-C nanocomposites could therefore be a promising nanoformulation for anticancer therapy and antibacterial applications. Of particular note is the potential of this platform to act as an antibiotic-free formulation for use against infections caused by a range of different bacterial pathogens. Given the anticancer activity of the platform, it may prove to be of great use as an oncotherapy supplement, helping manage both the disease condition and opportunistic bacterial infections. 


\section{Conflicts of interest}

There are no conflicts to declare.

\section{Acknowledgements}

This study was supported by the Research Fund of the Sri Lanka Institute of Nanotechnology (PRO0088). The authors would like to thank Dr Malini Damayanthi and Samantha Weerasinghe for their support in SEM imaging. Anticancer studies were supported by Prof. Preethi de Soysa, Department of Biochemistry, Faculty of Medicine, University of Colombo.

\section{References}

1 B. Chauhan, G. Kumar, N. Kalam and S. H. Ansari, J. Adv. Pharm. Technol. Res., 2013, 4, 4-8.

2 A. G. Atanasov, B. Waltenberger, E. M. Pferschy-Wenzig, T. Linder, C. Wawrosch, P. Uhrin, V. Temml, L. Wang, S. Schwaiger, E. H. Heiss, J. M. Rollinger, D. Schuster, J. M. Breuss, V. Bochkov, M. D. Mihovilovic, B. Kopp, R. Bauer, V. M. Dirsch and H. Stuppner, Biotechnol. Adv., 2015, 33, 1582-1614.

3 T. Kurita and Y. Makino, Anticancer Res., 2013, 33, 28072822.

4 M. Kundu, P. Sadhukhan, N. Ghosh, S. Chatterjee, P. Manna, J. Das and P. C. Sil, J. Adv. Res., 2019, 18, 161-172.

5 Y. Manolova, V. Deneva, L. Antonov, E. Drakalska, D. Momekova and N. Lambov, Spectrochim. Acta, Part A, 2014, 132, 815-820.

6 W.-H. Lee, C.-Y. Loo, M. Bebawy, F. Luk, R. Mason and R. Rohanizadeh, Curr. Neuropharmacol., 2013, 11, 338-378.

7 S. S. Bansal, M. Goel, F. Aqil, M. V. Vadhanam and R. C. Gupta, Cancer Prev. Res., 2011, 4, 1158-1171.

8 P. Somu and S. Paul, New J. Chem., 2019, 43, 11934-11948.

9 J. Jiang, J. Pi and J. Cai, Bioinorg. Chem. Appl., 2018, 2018, 118.

10 P. Anand, H. B. Nair, B. Sung, A. B. Kunnumakkara, V. R. Yadav, R. R. Tekmal and B. B. Aggarwal, Biochem. Pharmacol., 2010, 79, 330-338.

11 S. Bisht, G. Feldmann, S. Soni, R. Ravi, C. Karikar, A. Maitra and A. Maitra, J. Nanobiotechnol., 2007, 5, 1-18.

12 M. R. Gasco, Adv. Drug Delivery Rev., 2007, 59, 377-378.

13 M. Üner and G. Yener, Int. J. Nanomed., 2007, 2, 289-300.

14 P. Dahlman, Diss. - Chalmers Tek. Hoegsk., 2005, 50, 1-63.

15 A. Kunwar, A. Barik, R. Pandey and K. I. Priyadarsini, Biochim. Biophys. Acta, Gen. Subj., 2006, 1760, 1513-1520.

16 P. Santos, A. C. Watkinson, J. Hadgraft and M. E. Lane, Skin Pharmacol. Physiol., 2008, 21, 246-259.

17 A. K. Dash and G. C. Cudworth, J. Pharmacol. Toxicol. Methods, 1998, 40, 1-12.

18 H. J. Anthony, J. Pharm. Sci., 2013, 102, 1165-1172.

19 Y. Li, Z. Lin, G. Gong, M. Guo, T. Xu, C. Wang, M. Zhao, Y. Xia, Y. Tang, J. Zhong, Y. Chen, L. Hua, Y. Huang, F. Zeng and B. Zhu, J. Mater. Chem. B, 2019, 7, 4252-4262.
20 A. Sirelkhatim, S. Mahmud, A. Seeni, N. H. M. Kaus, L. C. Ann, S. K. M. Bakhori, H. Hasan and D. Mohamad, Nano-Micro Lett., 2015, 7, 219-242.

21 X. Cai, Y. Luo, W. Zhang, D. Du and Y. Lin, ACS Appl. Mater. Interfaces, 2016, 8, 22442-22450.

22 X. Xu, D. Chen, Z. Yi, M. Jiang, L. Wang, Z. Zhou, X. Fan, Y. Wang and D. Hui, Langmuir, 2013, 29, 5573-5580.

23 A. Lipovsky, Z. Tzitrinovich, H. Friedmann, G. Applerot, A. Gedanken and R. Lubart, J. Phys. Chem. C, 2009, 113, 15997-16001.

24 V. Lakshmi Prasanna and R. Vijayaraghavan, Langmuir, 2015, 31, 9155-9162.

25 P. Rai, S. K. Tripathy, N. H. Park, K. J. O, I. H. Lee and Y. T. Yu, J. Mater. Sci.: Mater. Electron., 2009, 20, 967-971.

26 A. Umar, S. H. Kim, E. Suh and Y. B. Hahn, Chem. Phys. Lett., 2007, 440, 110-115.

27 R. Herrera-Rivera, M. D. L. L. Olvera and A. Maldonado, J. Nanomater., 2017, 2017, 16-20.

28 M. F. Khan, M. Hameedullah, A. H. Ansari, E. Ahmad, M. B. Lohani, R. H. Khan, M. M. Alam, W. Khan, F. M. Husain and I. Ahmad, Int. J. Nanomed., 2014, 9, 853864.

29 H. Kumar and R. Rani, Int. Lett. Chem., Phys. Astron., 2013, 19, 26-36.

30 R. T. De Silva, R. K. Dissanayake, M. M. M. G. P. G. Mantilaka, W. P. S. L. Wijesinghe, S. S. Kaleel, T. N. Premachandra, L. Weerasinghe, G. A. J. Amaratunga and K. M. N. De Silva, ACS Appl. Mater. Interfaces, 2018, 10, 33913-33922.

31 R. K. Dissanayake, P. B. Ratnaweera, D. E. Williams, C. D. Wijayarathne, R. L. C. Wijesundera, R. J. Andersen and E. D. de Silva, J. Appl. Pharm. Sci., 2016, 6, 001-006.

32 B. Budiarto, A. Mustopa and K. Tarman, J. Coastal Life Med., 2015, 3, 56-63.

33 W. D. Ratnasooriya, S. G. Ratnasooriya and R. Dissanayake, J. Coastal Life Med., 2016, 4, 623-627.

34 A. R. N. Silva, D. M. R. K. Dissanayake, C. B. Ranaweera, R. Pathirana and W. D. Ratnasooriya, Int. J. Pharm. Res. Allied Sci., 2015, 4, 54-57.

35 P. Soysa, I. S. De Silva and J. Wijayabandara, BMC Complementary Altern. Med., 2014, 14, 1-8.

36 J. O'Brien, I. Wilson, T. Orton and F. Pognan, Eur. J. Biochem., 2000, 5426, 5421-5426.

37 B. Liu and H. C. Zeng, J. Am. Chem. Soc., 2003, 125, 44304431.

38 X. M. Sun, X. Chen, Z. X. Deng and Y. D. Li, Mater. Chem. Phys., 2003, 78, 99-104.

39 M. Bitenc, P. Podbršček, Z. C. Orel, M. A. Cleveland, J. A. Paramo, R. M. Peters and Y. M. Strzhemechny, Cryst. Growth Des., 2009, 9, 997-1001.

40 S. H. Yu, J. Yang, Y. T. Qian and M. Yoshimura, Chem. Phys. Lett., 2002, 361, 362-366.

41 L. Guo, Y. L. Ji, H. Xu, P. Simon and Z. Wu, J. Am. Chem. Soc., 2002, 124, 14864-14865.

42 D. Mondelaers, G. Vanhoyland, H. Van Den Rul, J. D'Haen, M. K. Van Bael, J. Mullens and L. C. Van Poucke, Mater. Res. Bull., 2002, 37, 901-914. 
43 S. Lee, S. Jeong, D. Kim, S. Hwang, M. Jeon and J. Moon, Superlattices Microstruct., 2008, 43, 330-339.

44 Z. Wang, H. Zhang, Z. Wang, L. Zhang, J. Yuan, S. Yan and C. Wang, J. Mater. Res., 2003, 18, 151-155.

45 S. C. Pillai, J. M. Kelly, D. E. McCormack, P. O'Brien and R. Ramesh, J. Mater. Chem., 2003, 13, 2586-2590.

46 R. A. Bohara, N. D. Thorat and S. H. Pawar, RSC Adv., 2016, 6, 43989-44012.

47 T. X. Wang and T. J. Lou, Mater. Lett., 2008, 62, 2329-2331.

48 J. S. Jang, C. J. Yu, S. H. Choi, S. M. Ji, E. S. Kim and J. S. Lee, J. Catal., 2008, 254, 144-155.

49 K. Kakiuchi, E. Hosono, T. Kimura, H. Imai and S. Fujihara, J. Sol-Gel Sci. Technol., 2006, 39, 63-72.

$50 \mathrm{~S}$. Mahmud and M. J. Abdullah, in Nanotripods of Zinc Oxide, IEEE, 2006, vol. 2006, pp. 442-446.

51 L. Shen, H. Zhang and S. Guo, Mater. Chem. Phys., 2009, 114, 580-583.

52 Y. Ding and Z. L. Wang, Micron, 2009, 40, 335-342.

53 Z. L. Wang, J. Phys.: Condens. Matter, 2004, 16, 829-858.

54 A. Moezzi, M. Cortie and A. McDonagh, Dalton Trans., 2011, 40, 4871-4878.

55 J. Duan, X. Huang and E. Wang, Mater. Lett., 2006, 60, 19181921.

56 G. X. Tong, F. F. Du, Y. Liang, Q. Hu, R. N. Wu, J. G. Guan and X. Hu, J. Mater. Chem. B, 2013, 1, 454-463.

57 K. R. Soumya, S. Snigdha, S. Sugathan, J. Mathew and E. K. Radhakrishnan, 3 Biotech, 2017, 7, 1-10.

58 S. Ji, X. Lin, E. Yu, C. Dian, X. Yan, L. Li, M. Zhang, W. Zhao and L. Dian, J. Nanotechnol., 2018, 2018, 1-9.

59 R. S. Pandit, S. C. Gaikwad, G. A. Agarkar, A. K. Gade and M. Rai, 3 Biotech, 2015, 5, 991-997.

60 I. M. Krishnakumar, A. Ravi, D. Kumar, R. Kuttan and B. Maliakel, J. Funct. Foods, 2012, 4, 348-357.

61 Z. Emami-Karvani, Afr. J. Microbiol. Res., 2012, 5, 1368-1373. 62 P. J. P. Espitia, N. d. F. F. Soares, J. S. d. R. Coimbra, N. J. de Andrade, R. S. Cruz and E. A. A. Medeiros, Food Bioprocess Technol., 2012, 5, 1447-1464.

63 S.-Y. Teow, K. Liew, S. A. Ali, A. S.-B. Khoo and S.-C. Peh, J. Trop. Med. Hyg., 2016, 2016, 1-10.

64 P. Tyagi, M. Singh, H. Kumari, A. Kumari and K. Mukhopadhyay, PLoS One, 2015, 10, 1-15.
65 L. G. Morão, C. R. Polaquini, M. Kopacz, G. S. Torrezan, G. M. Ayusso, G. Dilarri, L. B. Cavalca, A. Zielińska, D. J. Scheffers, L. O. Regasini and H. Ferreira, Microbiologyopen, 2019, 8, 1-12.

66 B. Li, X. Li, H. Lin and Y. Zhou, Biomed Res. Int., 2018, 2018, 1-11.

67 P. P. Patil, J. V. Meshram, R. A. Bohara, S. G. Nanaware and S. H. Pawar, New J. Chem., 2018, 42, 14620-14629.

68 S. H. Mun, D. K. Joung, Y. S. Kim, O. H. Kang, S. B. Kim, Y. S. Seo, Y. C. Kim, D. S. Lee, D. W. Shin, K. T. Kweon and D. Y. Kwon, Phytomedicine, 2013, 20, 714-718.

69 K. M. Reddy, K. Feris, J. Bell, D. G. Wingett, C. Hanley and A. Punnoose, Appl. Phys. Lett., 2007, 90, 10-13.

70 P. Patra, S. Mitra, N. Debnath, P. Pramanik and A. Goswami, Bull. Mater. Sci., 2014, 37, 199-206.

71 G. Voicu, O. Oprea, B. S. Vasile and E. Andronescu, Dig. J. Nanomater. Biostruct., 2013, 8, 1191-1203.

72 E. El Nadi, E. A. H. Moussa, W. Zekri, H. Taha, A. Yones, M. S. Zaghloul, M. El Wakeel and R. M. Labib, Sarcoma, 2015, 2015, 1.

73 W. Huh and D. Egas Bejar, Adolesc. Health, Med. Ther., 2014, 5, 115-125.

74 A. J. Jasim Makkawi, N. H. Aysa and F.-A. G. Gassim, Asian J. Pharm. Clin. Res., 2019, 12, 535-539.

75 G. Chadalapaka, I. Jutooru, S. Sreevalsan, S. Pathi, K. Kim, C. Chen, L. Crose, C. Linardic and S. Safe, Int. J. Cancer, 2013, 132, 795-806.

76 P. Anand, S. G. Thomas, A. B. Kunnumakkara, C. Sundaram, K. B. Harikumar, B. Sung, S. T. Tharakan, K. Misra, I. K. Priyadarsini, K. N. Rajasekharan and B. B. Aggarwal, Biochem. Pharmacol., 2008, 76, 1590-1611.

77 R. L. Thangapazham, A. Sharma and R. K. Maheshwari, AAPS J., 2006, 8, 443-449.

78 S. V. Singh, X. Hu, S. K. Srivastava, M. Singh, H. Xia, J. L. Orchard and H. A. Zaren, Carcinogenesis, 1998, 19, 1357-1360.

79 Y. Li, Z. Lin, M. Zhao, T. Xu, C. Wang, L. Hua, H. Wang, H. Xia and B. Zhu, ACS Appl. Mater. Interfaces, 2016, 8, 24385-24393.

80 S.-H. Moon, W. J. Choi, S.-W. Choi, E. H. Kim, J. Kim, J.-O. Lee and S. H. Kim, Toxicol. Rep., 2016, 3, 430-438. 